\title{
Modified Pseudomonas agar: new differential medium for the detection/enumeration of Pseudomonas aeruginosa in mineral water
}

\author{
Rita Ramalho , Joaquim Cunha, Paula Teixeira, Paul A. Gibbs
}

Escola Superior de Biotecnologia, Universidade Católica Portuguesa, Rua António Bernardino de Almeida, 4200-072 Porto, Portugal

Keywords: Cetrimide; Mineral water; Nalidixic acid; P. aeruginosa; Pyocyanin

\begin{abstract}
Pseudomonas aeruginosa has been implicated as a foodborne and waterborne pathogen and is now considered a primary infectious agent. In the present study, the survival of $P$. aeruginosa inoculated in mineral water was evaluated by drop counts on Pseudomonas Agar Base (PAB), PAB with CN supplement X107, PAB with cetrimide, PAB with nalidixic acid, and these media with added $\mathrm{FeSO}_{4}$. Initial counts, before starvation, were the same in all media tested. Following this period, $P$. aeruginosa became sensitive to PAB with added cetrimide. The addition of $\mathrm{FeSO}_{4}$ did not improve the recovery of stressed $P$. aeruginosa but gave colonies a typical dark brown colour being easily differentiated from other species that can grow at $42{ }^{\circ} \mathrm{C}$. The modified Pseudomonas agar medium was also tested with several P. aeruginosa strains, other species of Pseudomonas, and other genera. Only $P$. aeruginosa strains (pyocyanin positive) produced the typical colonies. Our results demonstrate that Pseudomonas agar with ferrous sulphate, used for the differentiation of $P$. aeruginosa colonies, and nalidixic acid, used as an inhibitor of Gram-positive bacteria, might be a useful medium for the detection of injured $P$. aeruginosa in mineral water.
\end{abstract}

\section{Introduction}

Pseudomonas aeruginosa, as opportunistic bacteria, expresses virulence factors which are related to serious infections in humans, especially in immunocompromised individuals, and special precautions may be required to limit the exposure of these susceptible populations (Stiles, 1989, cited in Warburton et al.,

\footnotetext{
* Corresponding author. Tel.: +351-225580045; fax: +351225090351.

E-mail address: rramalho@morango.esb.ucp.pt (R. Ramalho).
}

1994a,b). It is widespread in natural and industrial environments and is able to grow in water (Vachée and Leclerc, 1995).

Contaminated water has frequently been described as the vehicle of infection (Havelaar et al., 1985). P. aeruginosa has been found in some mineral water in various countries, namely Brazil, Canada, France, Germany, Spain, the United States, and others (Hunter, 1993; Warburton et al., 1994a,b). Given the possibility of $P$. aeruginosa being a contaminant of bottled water, batches or brands of bottled water in which these organisms have been detected have been withdrawn from retail outlets in Europe (Manaia et al., 1990). 
Examination of drinking water for $P$. aeruginosa is not recommended as a routine procedure, but it is an indicator of good manufacturing processes and suitability for drinking of bottled water (Warburton et al., 1994a,b). According to the European Directive for mineral water (Anonymous, 1980), a natural mineral water shall be free of $P$. aeruginosa in any $250-\mathrm{ml}$ sample.

Conventional methods for the detection of P. aeruginosa use cetrimide as a selective agent. Pseudomonas Agar Base (PAB) medium is a modification of King's A medium (King et al., 1954) which uses magnesium and potassium salts to enhance production of the pigment pyocyanin. The addition of the supplement $(200 \mathrm{mg} / \mathrm{l}$ cetrimide, $15 \mathrm{mg} / 1$ nalidixic acid) makes the medium selective for $P$. aeruginosa (Goto and Enomoto, 1970). Pathogenic bacteria in water may be injured by exposure to sub-optimal temperature, salinity or toxic chemicals, or by starvation (McKay, 1992). Injury may result in an increased sensitivity to selective agents such as antibiotics and surface active agents (Ray and Johnson, 1984), and cells may also develop a requirement for some specific compounds for repair and subsequent growth. The use of selective media for the detection/enumeration of pathogens under stress conditions, such as those impaired by the aquatic environment, may therefore lead to their underestimation, which might represent, in some cases, a serious hazard to the public health.

In this study, a modified version of Pseudomonas agar was developed to improve $P$. aeruginosa recovery from mineral water. The performance of the new medium was also evaluated.

\section{Materials and methods}

\subsection{Starvation experiments}

\subsubsection{Water samples}

The mineral water used was collected at a still mineral water bottling plant in Portugal.

Sterilized glass bottles (Schott, Duran, Germany; $100 \mathrm{ml})$ containing filtered $(0.2-\mu \mathrm{m}$ pore size Nuclepore filters) and heated $\left(60{ }^{\circ} \mathrm{C} ; 20 \mathrm{~min}\right)$ mineral water (sterile water) were used (Colbourne et al., 1988; Moreira et al., 1994). Heating mineral water after filtration was necessary in order to obtain sterile water, since without that step, sterilisation could not be achieved due to the existence of autochthonous bacteria that could pass through $0.2-\mu \mathrm{m}$ pore size membrane filters (Jones et al., 1999). Sterilization of the water was needed since modified media were to be used and it was necessary to ensure that only $P$. aeruginosa would be counted.

\subsubsection{Bacterial strains and growth conditions}

A loop of $P$. aeruginosa ATCC 10145 and $P$. aeruginosa ATCC 27853 was inoculated separately into $20 \mathrm{ml}$ of Tryptic Soy Broth (Lab M, Bury, England) and incubated at $37^{\circ} \mathrm{C}$ for $24 \mathrm{~h}$. They were transferred to fresh TSB $(20 \mathrm{ml})$ at a final concentration of $1 \%(\mathrm{v} / \mathrm{v})$ and incubated as above. Each culture was harvested by centrifugation $(3000 \times g$ for $10 \mathrm{~min}$; PSELECTA, CENTROMIX) at ambient temperature, the supernatant fluid discarded, and the pellets resuspended in $20 \mathrm{ml}$ of sterile mineral water. This washing procedure was repeated three times with sterile mineral water before inoculation into glass bottles.

Four hundred microliters of cellular suspension was inoculated into sterilized glass bottles (Schott) containing $100 \mathrm{ml}$ of sterile mineral water and shaken vigorously to mix.

The bottles were aseptically sampled immediately after the addition of the suspension and at regular intervals during storage at room temperature $\left(\mathrm{ca} .20^{\circ} \mathrm{C}\right.$ ). Bottles were wrapped in aluminium foil to exclude light.

Samples were serially diluted in Maximal Recovery Diluent (LAB M) and viable counts were determined by the drop count technique (Miles and Misra, 1938) on Pseudomonas Agar Base (PAB; LAB M), PAB with CN supplement X107 (200 mg/l cetrimide; $15 \mathrm{mg} / \mathrm{l}$ nalidixic acid) (LAB M), PAB with cetrimide $(200 \mathrm{mg} / \mathrm{l})$, PAB with nalidixic acid $(15 \mathrm{mg} / \mathrm{l})$ (Sigma, St. Louis, USA), PAB with added $\mathrm{FeSO}_{4}$ $(0.05 \% \mathrm{w} / \mathrm{v})($ Sigma), PAB with $\mathrm{CN}$ supplement and $\mathrm{FeSO}_{4}(0.05 \% \mathrm{w} / \mathrm{v}), \mathrm{PAB}$ with cetrimide $(200 \mathrm{mg} / \mathrm{l})$ and $\mathrm{FeSO}_{4}(0.05 \% \mathrm{w} / \mathrm{v})$, and $\mathrm{PAB}$ with nalidixic acid $(15 \mathrm{mg} / \mathrm{l})$ and $\mathrm{FeSO}_{4}(0.05 \% \mathrm{w} / \mathrm{v})$. All plates were incubated at $41.5{ }^{\circ} \mathrm{C}$ for 24 and $48 \mathrm{~h}$. Since autoclaving oxidizes $\mathrm{Fe}^{2+}$ to $\mathrm{Fe}^{3+}, \mathrm{FeSO}_{4}$ was added to $\mathrm{PAB}$ as a filter-sterilized solution (Rayman et al., 1978).

Presented data are mean values obtained from three independent experiments. The error bars on the figures 
indicate the mean standard deviations for the data points.

\subsection{Measures of performance of the new medium}

\subsubsection{Specificity}

2.2.1.1. P. aeruginosa strains. In total, 43 P. aeruginosa strains were tested. P. aeruginosa 1688, 1718, 1728, 1742, 1801, 1802, 1916, 1919, 2280, 2282, 2283,2284 and 2285 were randomly chosen from the collection of cultures of the University of Surrey (UK). One P. aeruginosa was supplied from Serviços Microbiologia da Escola Superior de Biotecnologia, Porto (Portugal); two strains of $P$. aeruginosa were supplied by Laboratório Nacional de Investigaç ão Veterinária (LNIV) do Porto (Portugal); P. aeruginosa ATCC 10145 (1144), P. aeruginosa ATCC 27853 (1143), $P$. aeruginosa $\mathrm{LMG} 1242^{\mathrm{t}}$, and $P$. aeruginosa isolated from a clinical sample were supplied by the Departamento de Microbiologia da Universidade de Coimbra (Portugal); P. aeruginosa ESB1, NE44, NE45, NE46, NE47, NE49, NE50, NE51, NE52, NE53, NE54, NE55, NE56, NE63, NE64, NE65, NE67, NE68, NE69, NE70, NE71, NE73, NE75, and NE77 were supplied from the culture collection of Escola Superior de Biotecnologia.

\subsubsection{Other Pseudomonas spp. P. fluorescens} ATCC 13225, P. putida LMG 2257 (Arthrobacter sidepsulatus) were supplied by the Departamento de Microbiologia da Universidade de Coimbra; P. oleovarans $\mathrm{LMG} 2229^{\mathrm{t}}, P$. alcaligenes DSM $50342^{\mathrm{t}}, P$. pseudoalcaligenes DSM 50188 ${ }^{\mathrm{t}}$ P. fragi LMG 2191 ${ }^{\mathrm{t}}$, P. mendocina LMG $1223^{\mathrm{t}}$, P. stutrezi LMG $11199^{\mathrm{t}}$ were supplied from the cultures collection of Escola Superior de Biotecnologia.

\subsubsection{Other microorganisms. Salmonella typhi-} murium 7738/32, Yersinia enterocolitica Ger 0:3 PNS+, Escherichia coli NCTC 9001 were obtained from Leatherhead Food Research Association at Leatherhead (UK); Staphylococcus aureus NCTC 08532 was supplied by Serviços de Microbiologia da Escola Superior de Biotecnologia, Bacillus cereus, Streptococcus faecalis, Proteus vulgaris were supplied from the culture collection of Escola Superior de Biotecnologia.
2.2.1.4. Experimental conditions. A loop of all strains was inoculated into $20 \mathrm{ml}$ of Tryptic Soy Broth and incubated at $37{ }^{\circ} \mathrm{C}$ for $24 \mathrm{~h}$. These cultures were transferred to fresh TSB $(20 \mathrm{ml})$ at a final concentration of $1 \%(\mathrm{v} / \mathrm{v})$ and incubated as previously discussed. They were all streak-plated on Pseudomonas Agar Base and Pseudomonas Agar Base with 0.05\% $\mathrm{FeSO}_{4}(\mathrm{v} / \mathrm{v})$. Plates were incubated at 37 and $41.5{ }^{\circ} \mathrm{C}$ for 24 and $48 \mathrm{~h}$, and the colour of the colonies were recorded.

2.2.1.5. Pyocyanin production. Culture of P. aeruginosa were streak-plated on Pseudomonas Agar Base with $0.05 \% \mathrm{FeSO}_{4}(\mathrm{w} / \mathrm{v})$ and $\mathrm{K}_{2} \mathrm{HPO}_{4}(9 \mathrm{mM})$ (Merck, Darmstadt, F.R. Germany), as a way to correlate the colour of the colonies with the production or non-production of pyocyanin since $\mathrm{K}_{2} \mathrm{HPO}_{4}$ supresses its production (Burke et al., 1990). Plates were incubated at $41.5{ }^{\circ} \mathrm{C}$ for 24 and $48 \mathrm{~h}$ and the coloured colonies were recorded.

Two milliliters of $\mathrm{HCl}$ (0.1 M; PRONALAB; Lisboa, Portugal) was added to all colonies of $P$. aeruginosa grown on Pseudomonas Agar Base with $0.05 \%$ $\mathrm{FeSO}_{4}(\mathrm{w} / \mathrm{v})$ and the appearance on the colonies of a red-purple colour was recorded as a positive indication of the production of pyocyanin (Singleton and Sainsbury, 1997).

\subsection{Statistical analysis}

Statistical analysis was done with the ANOVA methodology using the Statview ${ }^{\mathrm{TM}}$ package (Abacus Concepts, Berkeley, CA) using the starvation time as independent variable. Bacterial counts were converted to $\log _{10} \mathrm{cfu} / \mathrm{ml}$.

\section{Results and discussion}

Enumeration of $P$. aeruginosa ATCC 10145 (1144) and ATCC 27853 (1143) during starvation in mineral water was performed in selective and non-selective media. Similar results were obtained for both strains. Therefore, results presented thereafter are only relative to P. aerugnosa 10145 .

After inoculation into the mineral water, the counts of $P$. aeruginos $a$ dropped by $2-3 \operatorname{logs}$, but over 2 days, the counts increased and remained constant for the 
Table 1

Viable counts $\left(\log _{10} \mathrm{cfu} / \mathrm{ml}\right)$ of $P$. aeruginosa ATCC 10145 (1144) starved in sterile mineral water

\begin{tabular}{|c|c|c|c|c|c|c|c|c|c|c|c|c|c|c|c|c|}
\hline \multirow[t]{2}{*}{$\begin{array}{l}\text { Time } \\
\text { (days) }\end{array}$} & \multicolumn{2}{|l|}{ PA } & \multicolumn{2}{|c|}{$\mathrm{PA}+\mathrm{FeSO}_{4}$} & \multicolumn{2}{|c|}{$\mathrm{PA}+\mathrm{CN}$} & \multicolumn{2}{|c|}{$\begin{array}{l}\mathrm{PA}+\mathrm{CN}+ \\
\mathrm{FeSO}_{4}\end{array}$} & \multicolumn{2}{|c|}{$\underline{\mathrm{PA}+\mathrm{NA}}$} & \multicolumn{2}{|c|}{$\begin{array}{l}\mathrm{PA}+\mathrm{NA}+ \\
\mathrm{FeSO}_{4} \\
\end{array}$} & \multicolumn{2}{|c|}{$\mathrm{PA}+\mathrm{C}$} & \multicolumn{2}{|c|}{$\begin{array}{l}\mathrm{PA}+\mathrm{C}+ \\
\mathrm{FeSO}_{4} \\
\end{array}$} \\
\hline & Mean & S.D. & Mean & S.D. & Mean & S.D. & Mean & S.D. & Mean & S.D. & Mean & S.D. & Mean & S.D. & Mean & S.D. \\
\hline 0 & 5.4 & 0 & 5.5 & 0 & 5.4 & 0 & 5.5 & 0 & 5.5 & 0 & 5.3 & 0 & 5.3 & 0 & 5.4 & 0 \\
\hline 1 & 3.7 & 0 & 3.8 & 0.17 & 3.7 & 0 & 3.8 & 0.17 & 3.7 & 0 & 3.7 & 0 & 4 & 0 & 4.06 & 0.12 \\
\hline 2 & 2.83 & 0.15 & 2.93 & 0.15 & 2.53 & 0.06 & 2.46 & 0.45 & 2.76 & 0.25 & 2.46 & 0.45 & 2.6 & 0.26 & 2.7 & 0.35 \\
\hline 3 & 3.1 & 0.04 & 3.13 & 0.06 & 3.2 & 0 & 3.06 & 0.06 & 3.1 & 0 & 2.83 & 0.06 & 3.23 & 0.06 & 3.26 & 0.06 \\
\hline 4 & 5.06 & 0.05 & 5.1 & 0 & 4.4 & 0 & 4.3 & 0 & 5.07 & 0.06 & 5 & 0 & 4.46 & 0.06 & 4.43 & 0.06 \\
\hline 5 & 5.46 & 0.20 & 5.53 & 0.23 & 4.2 & 0.4 & 4.23 & 0.45 & 5.5 & 0.2 & 5.5 & 0.2 & 4.5 & 0.2 & 4.5 & 0.17 \\
\hline 6 & 5.83 & 0.32 & 5.8 & 0.2 & 4.73 & 0.15 & 4.66 & 0.06 & 5.83 & 0.25 & 5.8 & 0.2 & 4.76 & 0.25 & 4.76 & 0.21 \\
\hline 7 & 5.83 & 0.11 & 5.93 & 0.15 & 4.36 & 0.15 & 4.33 & 0.06 & 5.9 & 0.1 & 5.83 & 0.12 & 4.9 & 0.17 & 4.9 & 0.17 \\
\hline 9 & 5.86 & 0.05 & 5.9 & 0.1 & 4.3 & 0.1 & 4.3 & 0 & 5.9 & 0.1 & 5.86 & 0.06 & 4.86 & 0.15 & 4.9 & 0.1 \\
\hline
\end{tabular}

Enumeration was made on $\mathrm{PAB}, \mathrm{PAB}$ with $\mathrm{FeSO}_{4}, \mathrm{PAB}$ with $\mathrm{CN}$, PAB with $\mathrm{CN}$ and FeSO 4 , PAB with nalidixic acid (NA), PAB with nalidixic acid and $\mathrm{FeSO}_{4}, \mathrm{PAB}$ with cetrimide (C) and $\mathrm{PAB}$ with cetrimide and $\mathrm{FeSO}_{4}$.

duration of the experiment (Table 1). An initial sharp decrease in the number of survivors of $P$. aeruginosa (Moreira et al., 1994) and of other contaminant organisms (Kersters et al., 1996) had already been recorded. This has been attributed to a requirement for a period of physiological adaptation to stress conditions (Matin et al., 1989; Roszak and Colwell, 1987) after which the mortality rate decreases. According to Watson et al. (1998), the maintenance of the viability relatively constant of starved S. aureus in water could be attributed to cryptic growth, where most of the cells die, providing nutrients for the survival of the remaining cells.

On the first days of the starvation experiment, no significant differences were observed between counts on the different media. On the subsequent days, the presence of cetrimide decreased counts (Table 1). It was therefore demonstrated that cetrimide was the selective compound responsible for the inhibition of starved cells since lower counts were obtained on all PAB media with cetrimide than on $\mathrm{PAB}$, or PAB with nalidixic acid only.

The differences in viable counts observed during starvation using different recovery media can be safely attributed to sublethal lesions in a large proportion of the population induced by stress factors in water since the initial counts were the same on all media. Cetrimide, a quaternary ammonium compound, apparently acts by disrupting the bacterial cell membrane with a resulting increase in permeability of the membrane. Gram-negative bacteria are generally less susceptible to biocides than Gram-positive species, mainly beca- use the outer membrane acts as a protective barrier. Cetrimide is generally not active against $P$. aerugino$s a$. In the present study, after starvation, cells become sensitive to this compound probably as a result of outer membrane damage.

These results support the earlier observation that one of the characteristics of injured microbes is loss of resistance to selective agents (Hurst, 1977; Barcina et al., 1997).

Reactive oxygen species such as superoxide and hydrogen peroxide can damage DNA, proteins, and membranes (Foster and Spector, 1995). Organisms can encounter potentially lethal levels of these intermediates from normal aerobic metabolism (Foster and Spector, 1995), or by inactivation of catalase (Rayman et al., 1978). According to Rayman et al. (1978), $\mathrm{FeSO}_{4}$ could be used in plating media to enhance the recovery of stressed microorganisms because it is a compound that is capable of degrading $\mathrm{H}_{2} \mathrm{O}_{2}$ and it is not toxic to the organisms. However, in our experiments, there were no significant differences between counts in media with and without $\mathrm{FeSO}_{4}(P<0.0001)$. Interestingly, this experiment led to the discovery that in the presence of $\mathrm{FeSO}_{4}$, colonies of $P$. aeruginosa appeared to be dark brown on PAB. In order to verify the possibility of PAB with $\mathrm{FeSO}_{4}$ being used as a new differential medium for the enumeration of $P$. aeruginosa, other various organisms were plated on this medium. As can be observed in Table 1, $P$. aeruginosa strains were the only organisms that gave the characteristic appearance. In this way, Pseudomonas agar without 
Table 2

Colour of the colonies of microorganisms grown on PAB with iron, PAB with iron and $\mathrm{K}_{2} \mathrm{HPO}_{4}$, and when acid was added to dark brown colonies on PAB with iron

\begin{tabular}{lll}
\hline & $\begin{array}{l}\text { Dark brown colonies } \\
\text { on PAB }+ \text { iron }\end{array}$ & $\begin{array}{l}\text { Dark brown colonies } \\
\text { on PAB }+ \text { iron }+\mathrm{K}_{2} \mathrm{HPO}_{4}\end{array}$ \\
\hline $\begin{array}{l}\text { P. aeruginosa LMG } \\
1242^{\mathrm{t}}, 1742,1718\end{array}$ & - & - \\
Other 40 P. aeruginosa & + & - \\
Other Pseudomonas spp. & - & - \\
Other genera & - & - \\
\hline
\end{tabular}

cetrimide with ferrous sulphate might be a new culturing medium that enhances the enumeration of $P$. aeruginosa from water samples. As, during starvation, counts of $P$. aeruginosa on PAB with and without nalidixic acid were the same, nalidixic acid can be added to PAB to improve the inhibition of the accompanying microbial flora (Goto and Enomoto, 1970). The incubation temperature of $42{ }^{\circ} \mathrm{C}$ may also increase its selectivity since most autochthonous bacteria of mineral water are psychrotrophic (Mavridou, 1992).

$P$. aeruginosa produces a number of pigments, two of which are pyocyanin and pyoverdin (Burke et al., 1990). Of all the organisms that were investigated, $P$. aeruginosa strains were the only ones presenting dark brown colonies in the presence of ferrous sulphate (except $P$. aeruginosa LMG 1242 ${ }^{\mathrm{t}}, 1742$, 1718; Table 2 ), independently of the temperature of incubation and of the media being evaluated, and since pyocyanin is the only factor present in $P$. aeruginosa that is absent in all other microorganisms tested, this pigment is probably responsible for the colonies colour.

In order to determine if the dark brown colour of the colonies was related to the production of pyocyanin, $P$. aeruginosa was spread-plated on $\mathrm{PAB}$ with $\mathrm{FeSO}_{4}$ and $\mathrm{K}_{2} \mathrm{HPO}_{4}$. Phosphate is a crucial nutrient in the regulation of secondary metabolite production, with higher levels inhibiting their formation (Whooley and McLoughlin, 1982). According to Burke et al. (1990), $\mathrm{K}_{2} \mathrm{HPO}_{4}$ suppresses the production of pyocyanin. In the presence of $\mathrm{K}_{2} \mathrm{HPO}_{4}$, colonies did not present the dark brown colour. These results demonstrated that pyocyanin was probably responsible for the dark brown colour of colonies when iron was present.

This was reinforced by the fact that when acid (which turns pyocyanin into a red-purple colour) was added to $P$. aeruginosa colonies, no change of colour was observed in the colonies of the three strains that did not produce the characteristic dark brown colour, suggesting that none or low amounts of pyocyanin were present. Only dark brown colonies became redpurple in the presence of acid (Table 2).

Typical dark brown colour might be given by iron stored within the cell. In the presence of iron, pyocyanin can be reduced by $P$. aeruginosa to leucopyocyanin, which in turn can reduce ferric iron into irontransferrin complexes. To transport iron into cells, the iron-transferrin complex binds to a cell-surface receptor and is internalized via a coated vesicle; the iron is subsequently released within the cell and may be stored as an iron-ferritin complex (Singleton and Sainsbury, 1997).

This study demonstrated that cells of $P$. aeruginosa become injured in mineral water which makes its accurate detection or enumeration unreliable on the selective media commonly used. Pseudomonas Agar Base with added nalidixic acid $(15 \mathrm{mg} / \mathrm{l})$ and $\mathrm{FeSO}_{4}$ $(0.05 \%)$ was proven to be an efficient selective and differential medium for the detection of $P$. aeruginosa (pyocyanin positive) in mineral water.

\section{Acknowledgements}

This work was financed by an EEC FAIR project CT-96-1037-'Improving methods and protocols used to insure the microbiological quality of bottled mineral waters'.

Financial support for author Ramalho was provided by a PhD fellowship issued by PRAXIS XXI (JNICT-BD/11496/97).

The authors acknowledge Sociedade das Águas de Luso and Danone Water Technology Center for their collaboration. 


\section{References}

Anonymous, 1980. Directive du Conseil du 15 Juillet 1980 relative au raprochement des legislation des Etats membres concernant l'exploitation et la mise dans le commerce des eaux minérales naturelles. Annexe 1 (80/777/CEE) Journal Officiel des Communautés Europeenes L229: 1-10.

Barcina, I., Lebaron, P., Vives-Rego, J., 1997. Survival of allochthonous bacteria in aquatic systems: a biological approach. FEMS Microbiol. Ecol. 23, 1-9.

Burke, R.M., Upton, M.E., McLoughlin, A.J., 1990. Influence of pigment production on resistance to ultraviolet irradiation in Pseudomonas aeruginosa ATCC 10145. Ir. J. Food Sci. Technol. 14, 51-60.

Colbourne, J.S., Trew, R.M., Dennis, P.J., 1988. Treatment of water for aquatic bacterial growth studies. J. Appl. Bacteriol. 65, 7985.

Foster, J.W., Spector, M.P., 1995. How Salmonella survive against the odds. Annu. Rev. Microbiol. 49, 145-174.

Goto, S., Enomoto, S., 1970. Nalidixic acid cetrimide agar. A new selective plating medium for the selective isolation of Pseudomonas aeruginosa. Jpn. J. Microbiol. 14, 65-72.

Havelaar, A.H., During, M., Delfgou-Van Asch, H.M., 1985. Comparative study of membrane filtration and enrichment media for the isolation and enumeration of Pseudomonas aeruginosa from sewage, surface water, and swimming pools. Can. J. Microbiol. $31,686-692$.

Hunter, P.R., 1993. The microbiology of bottled natural mineral waters. J. Appl. Bacteriol. 74, 3345-3352.

Hurst, A., 1977. Bacterial injury: a review. Can. J. Microbiol. 23, 936-944.

Jones, C.R., Chamberlain, A.H.L., Adams, M.R., 1999. An investigation of the presence of ultramicrocells in natural mineral water. Lett. Appl. Microbiol. 28, 275-279.

Kersters, I., Huys, G., Van Duffel, H., Vancanney, M., Kersters, K., Verstraete, W., 1996. Survival potential of Aeromonas hydrophila in freshwaters and nutrient-poor waters in comparison with other bacteria. J. Appl. Bacteriol. 80, 266-276.

King, E.O., Ward, M.K., Raney, D.E., 1954. Two simple media for the determination of pyocianine and fluorescein. J. Lab. Clin. Med. 44, 301-307.

Manaia, C.M., Nunes, O.C., Morais, P.V., Da Costa, M.S., 1990. Heterothopic plate counts and the isolation of bacteria from mineral waters on selective and enrichment media. J. Appl. Bacteriol. 69, 871-876.

Matin, A., Auger, E.A., Blum, P.H., Schultz, J.E., 1989. Genetic basis of starvation survival in nondifferentiating bacteria. Annu. Rev. Microbiol. 43, 293-316.

Mavridou, A., 1992. Study of the bacterial flora of a non-carbonated natural mineral water. J. Appl. Bacteriol. 73, 355-361.

McKay, A.M., 1992. Viable but non-culturable forms of potentially pathogenic bacteria in water. Lett. Appl. Microbiol. 14, 129-135.

Miles, A.A., Misra, S.S., 1938. The estimation of the bactericidal power of blood. J. Hyg. (Cambridge) 38, 732-749.

Moreira, L., Agostinho, P., Morais, P.V., Da Costa, M.S., 1994. Survival of allochthonous bacteria in still mineral water bottled in polyvinyl chloride (PVC) and glass. J. Appl. Bacteriol. 77, $334-339$.

Ray, B., Johnson, C., 1984. Survival and growth of freeze-stressed Campylobacter jejuni cells in selective media. J. Food Saf. 6, $183-195$.

Rayman, M.K., Aris, B., Derea, H.B., 1978. The effect of compounds which degrade hydrogen peroxide on the enumeration of heat-stressed cells of Salmonella senftenberg. Can. J. Microbiol. $24,883-885$.

Roszak, D.B., Colwell, R.R., 1987. Survival strategies of bacteria in the natural environment. Microbiol. Rev. 51, 365-379.

Singleton, P., Sainsbury, D., 1997. Dictionary of Microbiology and Molecular Biology, 2nd edn. John Wiley \& Sons.

Vachée, A., Leclerc, H., 1995. Propriétés antagonistes de la flore autochtone des eaux menérales naturelles vis-à-vis de Pseudomonas aeruginosa. J. Eur. Hydrol. 26, 327-338.

Warburton, D.W., Bowen, B., Konkle, A., 1994a. The survival and recovery of Pseudomonas aeruginosa and its effect upon salmonellae in water: methodology to test bottled water in Canada. Can. J. Microbiol. 40, 987-992.

Warburton, D.W., McCormick, J.K., Bowen, B., 1994b. Survival and recovery of Aeromonas hydrophila in water: development of methodology for testing bottled water in Canada. Can. J. Microbiol. 40, 145-148.

Watson, S.P., Clements, M.O., Foster, S.J., 1998. Characterization of the starvation-survival response of Staphylococcus aureus. J. Bacteriol. 180, 1750-1758.

Whooley, M.A., McLoughlin, A.J., 1982. The regulation of pyocyanin production in Pseudomonas aeruginosa. Eur. J. Appl. Biotechnol. 15, 161-166. 